\title{
Mit roter Nase zu Berühmtheit
}

Wer kennt sie nicht, die Geschichte von Rudolph dem rotnasigen Rentier? Seine glühend rote Nase wurde stets von den anderen Rentieren belächelt. Auch Santa Claus fürchtete, sie würde den Kindern Angst machen. Als dichter Nebel eines Tages die Sicht versperrte, kam Rudolphs Glanzstunde: Mit seiner leuchtenden Nase wies er dem Rentiergespann den Weg. So waren alle Geschenke rechtzeitig unter den Weihnachtsbäumen und die Kinder glücklich. Erfunden hat das Rentier ein amerikanischer Werbetexter 1939. Das gleichnamige Lied "Rudolph the Red-Nosed Reindeer" ist weltweit bekannt. Zur Weihnachtszeit läuft es rauf und runter und erfreut sich bis heute großer Beliebtheit.

Der Buchstabe der richtigen Antwort ist

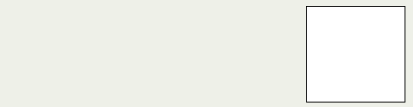

Name

Straße, Nr.

PLZ, Ort

Was ich noch sagen wollte ...

Coupon bitte ausfüllen und abschicken an Springer Medizin, Urban \& Vogel GmbH Redaktion Im Focus Onkologie - Quiz 12/2012 Aschauer Straße 30 • 81549 München Oder senden Sie uns eine E-Mail an doris.berger@springer.com

Einsendeschluss: 14.02.2013

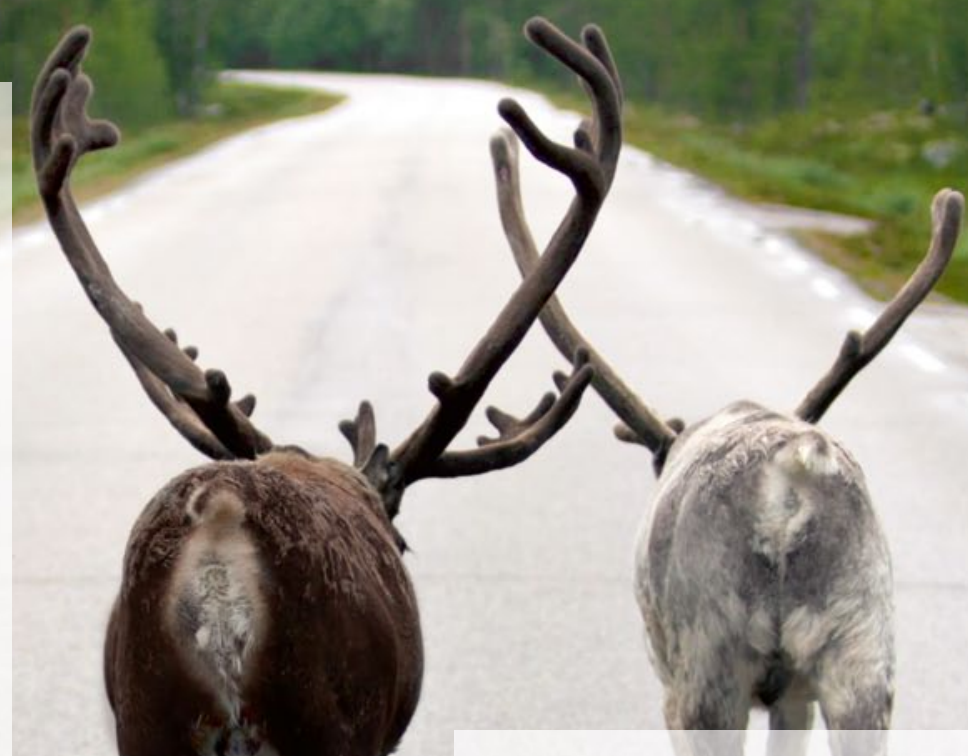

Was ist der wahre Grund für Rudolphs rote Nase?

A Rudolphs Nase ist wegen der eisigen Temperaturen gerötet

B Der Verzehr der roten Tundraflechte ist verantwortlich für die Nasenfarbe (C) $A$ N

C Ein parasitärer Befall der Atemwege ist verantwortlich für die Färbung

Alles, was Wissen schafft.

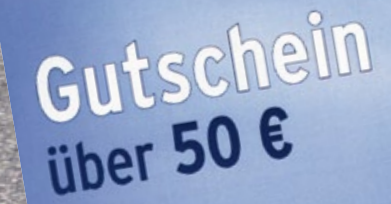

Q. Springer Medizin

Unter den richtigen

Einsendungen verlosen

wir drei Gutscheine über

50 Euro, die Sie für ein beliebiges Springer-Buch einlösen können.

Einsendeschluss ist der 14.02.2013.

\section{Lösung des Quiz 10/2012} Richtig war: B

Die Gewinne gehen an:

R. Schipper, 86653 Monheim H. List, 06120 Halle

U. Herwig, 22457 Hamburg Herzlichen Glückwunsch! 